\title{
Optimizing medicine use for people who are homebound: an evaluation of a pilot domiciliary Medicine Use Review (dMUR) service in England
}

This article was published in the following Dove Press journal: Integrated Pharmacy Research and Practice

\section{Asam Latif' \\ Baguiasri Mandane ${ }^{2}$ \\ Emma Anderson ${ }^{3}$ \\ Caroline Barraclough ${ }^{3}$ \\ Samantha Travis ${ }^{4}$ \\ 'School of Health Sciences, University of Nottingham, Nottingham, UK; ${ }^{2}$ University Hospitals of Leicester NHS Trust, Leicester, UK; ${ }^{3}$ Centre for Pharmacy Postgraduate Education, The University of Manchester, Manchester, UK; ${ }^{4} \mathrm{NHS}$ England, North Midlands, Mansfield, UK}

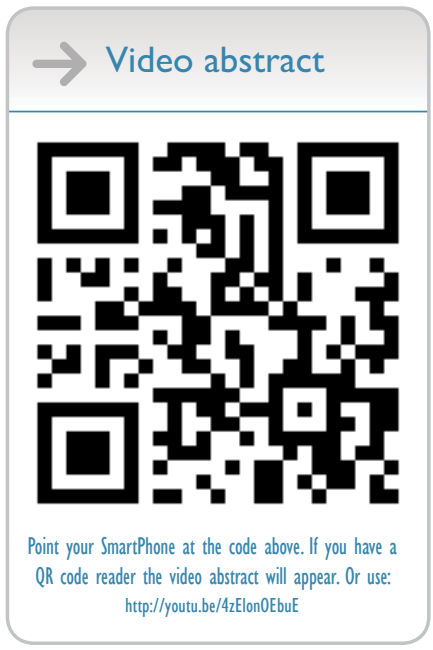

Correspondence: Asam Latif

School of Health Sciences, University of Nottingham, NG7 2HA, Nottingham, UK Tel +44 II58230495

Email asam.latif@nottingham.ac.uk
Background: As global life expectancy increases, older people with chronic diseases are being required to manage multiple and complex medicine regimes. However, polypharmacy raises the risk of medicine-related problems and preventable hospital admissions. To improve medicine use, English community pharmacies are commissioned to deliver Medicines Use Reviews (MURs), which are typically delivered from the pharmacy. People who are homebound rarely receive the service. This paper describes the uptake and impact of a pilot project that seeks to provide domiciliary Medicines Use Reviews (dMURs).

Methods: Participating pharmacists collected data on their dMUR activity over a 12-month period. Outcome measures (eg, adherence, side-effects, pharmacist assessment of preventable hospital admissions) were recorded. Pharmacists were also invited to submit written testimonies of their experiences of undertaking dMURs.

Results: Out of 433 possible pharmacies eligible to take part in the pilot, 186 pharmacies expressed an interest, and 91 actively engaged in providing the dMUR service. The total number of dMURs performed were 1092 (mean number performed by each pharmacy was 12). Two thirds of patients reported problems and concerns about side-effects and missed doses regarding their medicines. Pharmacists' assessment to prevent hospital admissions found that over one-third of the dMURs had contributed towards preventing either a possible or likely emergency hospital admission. Twelve pharmacists' testimonies were submitted providing context of the problems patients faced with medicines.

Discussion: dMURs are feasible and improve patient medicines use. The results indicate that dMUR potentially prevents hospital admissions and readmissions. dMURs offer an opportunity to support the self-care agenda and ensure homebound patients can successfully manage their medicines.

Keywords: community pharmacy, domiciliary Medicines Use Reviews, dMURs, hospital admission, medicines management.

\section{Introduction}

The world's population is rising and aging. The World Health Organization (WHO) estimates that, between 2015 and 2050, the proportion of the world's population over 60 years will nearly double from $12 \%$ to $22 \%$, and that the number of people aged 60 years and older will outnumber children younger than 5 years. ${ }^{1}$ For European health systems, it is acknowledged that an aging population, coupled with low birth rates and a higher life expectancy, is one of the greatest social, economic, and public health challenges of the 21 st century. ${ }^{2}$ With little evidence to suggest that older people today are experiencing better health than their parents, aging brings with it an inevitable 
rise in chronic health conditions. ${ }^{1}$ People with such medical conditions are the most intensive users of the most expensive health services. ${ }^{3}$ The global response to the epidemiological and economic impact of aging and associated morbidity has been described as inadequate. ${ }^{4}$ Innovative solutions are, therefore, needed to ensure older people have equitable access to good quality healthcare, and adequate support to manage their chronic long-term medical conditions.

Given the rising numbers of older people with chronic conditions, polypharmacy is becoming more prevalent. The burden of taking multiple medications is associated with greater healthcare costs, increased risk of adverse drug events (ADEs) and drug-interactions, reduced functional capacity, and medication non-adherence. ${ }^{5}$ Multi-morbidities and the accompanying polypharmacy have the potential to increase the risk of drug interactions and adverse drug reactions, together with impairing medication adherence and reduction in quality-of-life for patients. ${ }^{6,7}$ Work undertaken to optimize safe medication use highlights the value of appropriate polypharmacy (all medicines clinically indicated and accepted by the individual as improving their wellbeing), but cautions about problematic polypharmacy (multiple medicines inappropriately prescribed or where the intended benefits are not realized). ${ }^{7}$ Reconfiguring health professional roles and responsibilities is, therefore, necessary to ensure that medicines are used effectively. In the case of pharmacy, there has been an evident shift in the pharmacist's role, from the supply of medicines and provision of patient education involving acute medicines, towards consultation-type services for chronic medications. ${ }^{8}$

The English community pharmacy contractual framework is divided into essential, advanced, and locally commissioned services. Essential services include dispensing medicines and appliances and disposal of unwanted medicines, whereas the "advanced" services include consultation-style Medicine Use Reviews (MURs). MURs were commissioned in 2005, and give community pharmacists an opportunity to contribute to medicines optimization. ${ }^{9}, 10$ However, MURs are typically delivered from a community pharmacy, and patients who are homebound may not be receiving the service. ${ }^{11} \mathrm{~A}$ domiciliary Medicines Use Review (dMUR) service was, therefore, designed, and this paper reports the uptake of dMUR by pharmacy teams, investigates the impact of the dMUR on medicines optimization (eg, patient reported adherence to medicines and side-effects, etc.), and presents the lessons that have been learned about commissioning such services in the future.

\section{Medicines Use Reviews (MURs)}

An MUR typically involves an annual face-to-face patientpharmacist consultation to improve the patient's knowledge of prescribed and over-the-counter medicines and their use (Box 1). Pharmacies are currently entitled to claim a fee of $£ 28$ for each MUR they undertake with patients, and are able to conduct up to a maximum of 400 reviews annually. In 2011, the MUR specifications were changed in order to target more vulnerable patients. Under the new terms, at least $50 \%$ of all MURs undertaken by each pharmacy should be with patients within these groups (from April 1, 2015 this was raised to at least 70\%): (1) patients taking medicines associated with hospital admissions (non-steroidal anti-inflammatory drugs, anticoagulants, antiplatelets, diuretics); (2) patients recently discharged from hospital and who have had changes made to their medicines; and (3) patients with respiratory disease. A fourth target group was agreed in September 2014 (cardiovascular risk) and was implemented from January 1, 2015.

\section{The domiciliary MURs (dMURs) pilot}

A dMUR service was developed and led by the NHS England Local Professional Network Chair (Pharmacy), in response to concerns that the target groups did not include patients who are homebound. The dMUR was, therefore, specifically designed to target people unable to attend the pharmacy, ie, homebound patients and those who were not receiving care from a residential/nursing home. Patients could self-refer, or be identified by their pharmacists, GPs, carers, or secondary care professionals. Patients were required to provide written informed consent to the service delivery. This also included consent for anonymized data to be collected and evaluated.

Patients were eligible for a dMUR if they were taking at least six medicines rather than only two as per the MUR. This change to the original service specification was made on the understanding that, first, patients taking a greater number of

\section{Box I The purpose of the MUR service}

The MUR aims, with the patient's agreement, to improve his or her knowledge and use of drugs. This purpose is to be achieved through:

I. Establishing the patient's actual use, understanding about, and experience of taking his or her medications;

2. Identifying, discussing, and resolving poor or ineffective use of medicines by the patient;

3. Identifying side-effects and drug interactions that may affect patient compliance; and

4. Improving the clinical and cost-effectiveness of prescribed medicines, thereby reducing the wastage of such drugs. ${ }^{12}$

Abbreviation: MUR, Medicine Use Review. 
medicines tend to experience more problems, ${ }^{13,14}$ and, second, the minimum number of medicines was increased to discourage "gaming," which has been highlighted by others, where pharmacists opportunistically select patients on fewer medicines that can be conducted quickly and conveniently. ${ }^{15,16} \mathrm{As}$ part of the dMUR, pharmacists were encouraged to review the ordering, collection, and delivery systems for these patients. To be able to offer the service, pharmacists were required to have completed an enhanced Disclosure and Barring Service check, which was paid for by the local NHS England Direct Commissioning Operations (DCO) team.

Services offered by a pharmacy often require additional pharmacist's time or resources, and it has been suggested that this should be considered in developing a new service. ${ }^{17}$ For example, one study describing how pharmacists spent their time in practice found that pharmacists spent the majority of their time on many technical aspects of the dispensing process, as opposed to cognitive, patient-centered, tasks. ${ }^{18}$ It is acknowledged that there might also be barriers to pharmacists being able to conduct dMURs as they would be unable to supervise pharmacy activities, including sales of over-the-counter medicines. Some have suggested that role clarity and professional responsibility need to be considered when designing changes to supervision. ${ }^{19}$ To ensure sufficient remuneration was in place to try to overcome the barriers to participation, the dMUR service included an additional $£ 56$ reimbursement, in addition to the standard MUR payment (£28).

\section{Methods}

The dMUR service was advertised to all pharmacies commissioned by the local NHS England office, across an area covering the geography of ten clinical commissioning groups. It was also advertised through the Local Pharmaceutical Committee website and a mail shot from the NHS England contracting team. Pharmacies within the Nottinghamshire and Derbyshire region that expressed interest were provided with a detailed service specification and guidance, in the form of a simple checklist which included advice on what to do before the visit (eg, confirming appointment times, appropriate paperwork, journey guidance, ie, having a satnav). Advice was also provided on useful equipment that may be necessary (eg, bringing with them clinical waste buckets), and suggestions for taking healthy lifestyle leaflets.

\section{Data collection}

Pharmacists collected data on their dMURs over a 12-month period from April 2016 to March 2017. During the dMUR, pharmacists recorded several outcome measures using a pragmatic instrument on a paper template. Demographic data was collected, as well as medicines-related outcomes (eg, patient reported problems with medicines, side-effects, and adherence). In addition, pharmacists used a quantitative scoring method to self-assess the risk that a patient had of a hospital admission, and the impact the dMUR had on reducing this risk. The scoring system, which was devised by the pilot lead, was as follows:

- Score 1 = no likelihood of emergency hospital admission prevented.

Examples include: providing a compliance device to aid administration of eye drops; stopping any unnecessary food supplements; providing lifestyle and diet advice.

- Score 2 = possible prevention of emergency hospital admission.

Examples include: advising on tackling poor inhaler technique; advising on how best to manage long-term steroid use; suggesting prescribing guidance, such as commencement of bisphosphonates.

- Score 3 = likely to prevent an emergency hospital admission.

Examples include: incorrect insulin usage leading to diabetic related complications; poor adherence to antiepileptic medicines. The scoring system helped to analyse baseline data on the potential of the dMUR being able to prevent hospital admissions or possible readmissions.

Upon completion of the dMUR, pharmacists recorded any actions as a result of the dMUR (eg, provision of patient education, referrals to other health professionals).

To evaluate the service further, all participating pharmacists were asked to qualitatively report their dMUR experiences through written reflective testimonials. In particular, we wanted to understand the problems patients had encountered, as well as the solutions pharmacists offered. This was an optional element, in addition to the quantitative data they were required to complete.

\section{Survey data analysis}

All the information recorded by pharmacists was inputted into an electronic database (PharmOutcomes ${ }^{\circledR}$ ) for analysis. PharmOutcomes is a web-based system which helps commissioners audit and manage pharmacy services. Following data entry and cleaning, summary demographics and characteristics of the sample were initially described. All variables were categorical. The demographic variables were then summarized using frequencies and proportions for the categorical variables. For the outcome variables of interest, 
the proportion responding positively was computed alongside its $95 \%$ confidence interval.

\section{Data analysis of testimonials}

Submitted testimonies were then collated, analyzed, and coded inductively by AL and BM. Codes were constructed based upon what was reported and coded extracts systematically read through, and the contents were condensed so that all the different issues raised were recorded. Consideration was then given to how these issues might be grouped together in broader themes, which were then synthesized and narrated.

\section{Ethical approval}

The dMUR service was approved by the NHS England DCO team. Being a service evaluation, Health Research Authority ethical approval was not necessary.

\section{Results}

Out of a total 433 possible pharmacies eligible to take part in the pilot, 186 pharmacies expressed interest. Of these, 91 actively engaged in providing the dMUR service. The majority of patient recruitment was through community pharmacies (91.7\%) (Table 1), and the total number of dMURs performed were 1092 (mean number of dMURs performed by each pharmacy $=12$ ).

\section{Demographic data (Table I)}

The majority of the patients were female (68\%), over the age of $75(76.9 \%)$, and categorized as White British (89.2\%). The majority of the carer arrangements were through the family (44.1\%), over a third did not have any arrangements (39.8\%), and over a quarter (29.8\%) had either daily visits by care agencies, informal carers/friends, or periodic district nursing visits.

\section{Medicine-related outcomes from dMUR (Table 2)}

Approximately two thirds of patients reported problems and concerns, side-effects, and missed doses regarding their medicines (63.7\%). Over a quarter of patients $(27.8 \%)$ were also identified as having stock piles of medicines or expired medicines, which were consequently removed by the pharmacists.

\section{Pharmacists' actions following the dMUR (Table 3)}

Over half of patients receiving a dMUR (584) received patient advice with their medicines. Over $40 \%$ of patients $(42.5 \%)$
Table I Demographic data $(n=1062)$

\begin{tabular}{|c|c|c|}
\hline Variable & $\begin{array}{l}\text { Sample } \\
\text { proportion }\end{array}$ & $\%$ Positive \\
\hline \multicolumn{3}{|l|}{ Age } \\
\hline$<24$ & 6 & 0.6 \\
\hline $25-34$ & 1 & 0.1 \\
\hline $35-44$ & 5 & 0.5 \\
\hline $45-54$ & 21 & 2.0 \\
\hline $55-64$ & 50 & 4.7 \\
\hline $65-74$ & 162 & 15.2 \\
\hline $75+$ & 817 & 76.9 \\
\hline \multicolumn{3}{|l|}{ Gender } \\
\hline Female & 722 & 68 \\
\hline Male & 340 & 32 \\
\hline \multicolumn{3}{|l|}{ Ethnicity } \\
\hline White - British & 947 & 89.2 \\
\hline White - Irish/Other & 27 & 2.5 \\
\hline Black or Black British - Caribbean & 15 & 1.4 \\
\hline Asian or Asian British - Pakistani/Other & 7 & 0.7 \\
\hline Prefer not to say/Not stated & 52 & 4.9 \\
\hline Missing data & 14 & 1.3 \\
\hline \multicolumn{3}{|l|}{$\begin{array}{l}\text { Possible care arrangements (all that } \\
\text { apply) }\end{array}$} \\
\hline None & 423 & 39.8 \\
\hline Family & 468 & 44.1 \\
\hline Daily visits by Care Agency & 162 & 15.3 \\
\hline Informal carer/friend & 95 & 8.9 \\
\hline Periodic District Nursing & 60 & 5.6 \\
\hline \multicolumn{3}{|l|}{ Service referral by } \\
\hline Community Pharmacy & 974 & 91.7 \\
\hline Patient/patient's representative & 30 & 2.8 \\
\hline GP practice & 28 & 2.6 \\
\hline Social Services (Community Care Team) & 14 & 1.3 \\
\hline Secondary care & 8 & 0.8 \\
\hline Other (eg, 0 district nurses) & 8 & 0.8 \\
\hline
\end{tabular}

Table 2 Medicine-related outcomes from dMUR $(n=1062)$

\begin{tabular}{|c|c|c|}
\hline Variable & $\begin{array}{l}\text { Sample } \\
\text { proportion }\end{array}$ & $95 \% \mathrm{Cl}$ \\
\hline Patient reported problems and concerns & $322(30.3 \%)$ & $27.6-33.1$ \\
\hline Reported side-effects & $178(16.8 \%)$ & $14.6-19.0$ \\
\hline Reported missed doses (non-adherence) & $177(16.7 \%)$ & $14.5-18.9$ \\
\hline $\begin{array}{l}\text { Identification of discontinued medicines } \\
\text { and their removal }\end{array}$ & 307 (28.9\%) & $26.2-31.6$ \\
\hline \multicolumn{3}{|l|}{ Other patient issues (all that apply) } \\
\hline $\begin{array}{l}\text { Security (ie, controlled drugs and safe } \\
\text { suggested) }\end{array}$ & $6(0.6 \%)$ & $0.1-1.1$ \\
\hline Stock piling medicines & $156(14.7 \%)$ & $12.6-16.8$ \\
\hline Expired medicines & $139(13.1 \%)$ & $|I|-.|5|$. \\
\hline Other & $109(10.3 \%)$ & $8.5-12.1$ \\
\hline
\end{tabular}

Abbreviation: dMUR, domiciliary Medicine Use Review.

were reviewed for medicine support (eg, medicines delivery). More than half of patients had assessments to improve medicines' adherence (eg, a review of compliance, inhaler technique, large print labels, etc.).

In addition to the dMUR, two thirds of patients received a medicines' cabinet check and/or had their medicines 
Table 3 Pharmacists' actions following dMUR $(n=1062)$

\begin{tabular}{|c|c|c|}
\hline Variable & $\begin{array}{l}\text { Sample } \\
\text { proportion }\end{array}$ & $95 \% \mathrm{Cl}$ \\
\hline \multicolumn{3}{|l|}{ Pharmacists' actions (all that apply) } \\
\hline Patient education & $584(55.0 \%)$ & $52.0-58.0$ \\
\hline Review of support (delivery, etc.) & $45 \mathrm{I}(42.5 \%)$ & $39.5-45.5$ \\
\hline Review of compliance aid/introduction & $249(23.4 \%)$ & $20.9-25.9$ \\
\hline Inhaler technique check & $186(17.5 \%)$ & $15.2-19.8$ \\
\hline 7 day scripts/28 day scripts & $85(8.0 \%)$ & $6.4-9.6$ \\
\hline Change of dose form recommended & $58(5.5 \%)$ & $4.1-6.9$ \\
\hline Large print labels & $32(3.0 \%)$ & $2.0-4.0$ \\
\hline Easy open caps & $18(1.7 \%)$ & $0.9-2.5$ \\
\hline Medicines chart MARR? & $23(2.2 \%)$ & $1.3-3.1$ \\
\hline None required & $272(25.6 \%)$ & $23.0-28.2$ \\
\hline Other & $65(6.1 \%)$ & $4.7-7.5$ \\
\hline \multicolumn{3}{|l|}{$\begin{array}{l}\text { Additional service to the dMUR (all } \\
\text { that apply) }\end{array}$} \\
\hline Medicines Cabinet check & $470(44.3 \%)$ & $41.3-47.3$ \\
\hline Medicines synchronization & $214(20.2 \%)$ & 17.8-22.6 \\
\hline NMS & $10(0.9 \%)$ & $0.3-1.5$ \\
\hline \multicolumn{3}{|l|}{ Referrals } \\
\hline None necessary & $804(75.7 \%)$ & $73.1-78.3$ \\
\hline GP & $230(21.6 \%)$ & $19.1-24.1$ \\
\hline Social Care support & $5(0.5 \%)$ & $0.1-0.9$ \\
\hline Hospital support service & $3(0.3 \%)$ & $-0.0-0.6$ \\
\hline District Nursing team & $3(0.3 \%)$ & $-0.0-0.6$ \\
\hline Other & $17(1.6 \%)$ & $0.9-2.4$ \\
\hline \multicolumn{3}{|l|}{$\begin{array}{l}\text { Pharmacists' assessment of prevented } \\
\text { hospital admissions }\end{array}$} \\
\hline $\begin{array}{l}\text { I = no likelihood of emergency hospital } \\
\text { admission prevented }\end{array}$ & $687(64.7 \%)$ & $61.8-67.6$ \\
\hline $\begin{array}{l}2 \text { = possible prevention of emergency } \\
\text { hospital admission }\end{array}$ & $298(28.1 \%)$ & $25.4-30.8$ \\
\hline $\begin{array}{l}3=\text { likely to prevent an emergency hospital } \\
\text { admission }\end{array}$ & 77(7.2\%) & $5.7-8.8$ \\
\hline
\end{tabular}

Abbreviations: dMUR, domiciliary Medicine Use Review; NMS, new medicines service.

synchronized. Approximately one quarter of patients were referred to their GP, social care, hospital support service, or district nurse team.

Analysis of the pharmacists' assessment to prevent hospital admissions found that over one third (35.3\%) had either contributed towards preventing either a possible or likely emergency hospital admission.

\section{Pharmacists' testimonies}

A total of 12 pharmacists' testimonies were analysed. Every pharmacist reported and described problems around the patients' medication. These ranged from minor issues (ie, simple advice on inhaler technique) to more substantial concerns over medicine non-adherence, confusion over dosage regimens, and problems with medicines at the primarysecondary interface. In addition to medicines-related problems, pharmacists also identified problems beyond the scope of the dMUR such as catheter and stoma complications.

\section{Problems with medicines}

Pharmacists highlighted a range of medication issues in the testimonies. Non-adherence and other medicines optimization issues were resolved using patient education, applying compliance aids, or referring the patient to their GP:

Her inspiration force was far too high ... and hitting the back of her throat. After training, we managed to reduce the inspiration force and improve inhaler technique. SU was also taking two Lansoprazole capsules, instead of the one capsule daily as prescribed ... SU was also very confused what Atorvastatin was for and how to take it. Therefore, I advised SU why she was taking it and how to take it. [SU Pharmacist]

Also, the patient was confused as to whether he should be taking his ferrous tablets still or not. As a result, I referred this issue to his GP to ascertain whether ferrous tablets were required still or not. [Pharmacist (1)]

\section{Managing side-effects}

Most pharmacists' accounts mentioned that the patient was experiencing side-effects from their prescribed medicines. Pharmacists were able to both assess and address these issues, and so improve medicine adherence:

Since starting the chemotherapy/Enoxaparin, the patient had been suffering from a severe allergy/itching. It was so severe that the patient was prepared to stop the chemotherapy so that the patient can live without the side-effects. She had been given Eurax ${ }^{\circledR}$ cream to help control the itchiness, but it was now becoming more wide-spread, so I advised to take cetirizine as well. I then chased up the patient a few days later, who said it was making a huge difference! The patient is now happy to continue with her chemotherapy. [Pharmacist (2)]

Also, his Spiriva was causing the patient to develop a dry mouth from the inhaler. As a result, I advised the patient to rinse his mouth out and increase fluid intake. His GP had already advised the patient to increase fluid intake, so I asked him to drink a glass of water in between his cups of tea. RM also smokes, so I have signposted him to the New Leaf service currently available in Nottinghamshire.

[Pharmacist (3)]

\section{Prevention of possible hospital admissions and readmissions}

Commentaries also revealed how the pharmacist intervened to prevent serious adverse drug events and how this led to possible prevention of a hospital admission, particularly, 
lack of knowledge around medicines and, thus, compliance related problems.

This dMUR visit probably stands out the most as being the most alarming visit I have carried out. When I was going through her medication list, she couldn't name any medicines she was taking, what they were for, or when she takes any (...) cabinet in the living room and said "I just take a selection of five tablets from this tray," which was very concerning, as she could potentially take five of the same tablets (...) This visit enabled us to identify a big issue with compliance and patient safety that was "under the radar" for a while, resulting in potentially avoiding an inevitable hospital admission. [Pharmacist (4)]

Findings also revealed the dMUR to have had an impact on the prevention of potential hospital re-admissions. In these cases, pharmacists identified where medicine reconciliation had failed, and intervened to rectify the problem:

This patient was completely confused. She didn't know whether to keep on taking Warfarin after her hospital discharge. (...) Also, she had bisoprolol on her discharge letter, but didn't have any at home. (...) This visit would have most probably prevented the patient being admitted to hospital again, as without this the patient would have not been taking her Warfarin or bisoprolol. [Pharmacist (5)]

\section{Discussion}

The evaluation of the dMUR pilot suggests that this program is feasible, and that pharmacists were able to adopt the dMUR within their practice. Analysis of the results suggest that the dMUR was successful at improving medicine adherence, managing side-effects and reducing medication errors. In the elderly, the burden of multiple medications has been associated with greater healthcare costs and an increased risk of ADEs, drug-interactions, medication non-adherence, reduced functional capacity, and multiple geriatric syndromes. ${ }^{5}$ The Murray review and the community pharmacy forward view have highlighted the role that community pharmacists could play in managing patient's medicines, and facilitation of personalized and integrated care for patients with long-term conditions. ${ }^{20}$ One such role is the community pharmacy is the MUR service. However, it has been recognized that the current service framework is not addressing the needs of older people who are homebound, and that local adaptation of the MUR service to encourage pharmacists to target this subgroup of patients could be a way of improving care. Others have suggested that patients who are homebound could be less likely to be able to access the MUR service, and so are more likely to be disadvantaged when compared to the general population. ${ }^{21}$ The dMUR service may address the well-known issues that homebound people face in leaving the home and having varying degrees of confinement. ${ }^{22} \mathrm{~A}$ lack of contact with the healthcare system and other social interactions can also make people progressively more ill, lonely, and depressed. ${ }^{23}$

The results also support the growing notion that pharmacists can play a significant role in reducing hospital admissions and readmissions. ${ }^{13,14}$ This is important, because it is well recognized that transferring patients between care providers, such as on hospital admission or discharge, represents a high-risk area period, potentially leading to adverse drug events. For example, It has been found that around half of the medication errors that occur in hospital are estimated to occur on admission or discharge.$^{24}$ Medication reconciliation at transitions of care (admission, transfer, and discharge) aims to ensure the correct medications are supplied to the patient at all transition points, avoid medication errors such as omissions, duplications, dosing errors, or drug interactions, and, therefore, to promote seamless care. ${ }^{25}$ In the present study, most patient were referred by the pharmacist. In order to improve rates of referrals from other health professionals, the value of dMURs should be more widely promoted. In addition, it has been suggested that the current provisions for post discharge MURs are more likely to disadvantage older people, particularly those who are homebound. ${ }^{26}$

Further research is needed to validate the findings of this pilot, to explore the barriers to service update and establish whether the dMUR service is cost-effective.

\section{Strengths and limitations}

This pilot study shows that dMURs reduce the perceived risk of medicine-related hospitalization and that the intervention was found to be feasible in practice. This finding should be viewed with caution as the tool used to collect information about the dMUR service and the score of hospital admission risk was not validated. Furthermore, we do not know how this score may have been interpreted by individual pharmacists, and so there may be a potential lack of consistency. Nevertheless, this was a pragmatic instrument, allowing a measure of self-reported efficacy to be established. We observed a relatively low number of pharmacies participating, which supports the idea that new work practices often take time to imbed within practice. ${ }^{27}$ It may also indicate that pharmacies may not yet have reconfigured levels of support or organizational infrastructure to comfortably undertake such services outside their pharmacies. 
Looking more closely at ethnicity, the results suggest most of the patients who received a dMUR were of White British (89.2\%) ethnicity. This could be a potential limitation of the service, that patients from underserved communities, eg, those from Black, Asian, and Minority Ethnic (BAME) communities, may not have been offered the service. An alternative explanation could be that this was simply due to the collection of data from rural areas (where the proportion of BAME patients is lower) compared to inner city areas. Another limitation was that the pilot study did not seek to collect any comparison data with the usual MUR service that are delivered from pharmacies. Further research is, therefore, necessary to assess how more effective a dMUR was over a MUR at reducing medicinerelated problems.

Although the findings from this study did not show any concerns around pharmacists visiting patient's home, a review of lone working policies would need to address any safety concerns of delivering the service within the patient's home environment.

\section{Conclusion}

DMURs reduced the pharmacists' self-assessed risk of hospital admissions and readmissions and reduced medicinerelated problems. Further evaluation and expansion of this pilot is required to determine its cost-effectiveness.

\section{Acknowledgments}

We acknowledge and thank all the participants and organizations that took part in this evaluation. We are particularly indebted to the community pharmacies who participated and collected data for this evaluation.

\section{Author contributions}

ST conceptualized the dMUR service and oversaw data collection. All authors contributed toward data analysis, drafting, and critically revising the paper and agree to be accountable for all aspects of the work.

\section{Disclosure}

The authors report no conflicts of interest in this work.

\section{References}

1. World Health Organization (WHO). Fact sheet $N^{\circ} 404$ : Ageing and health. Geneva: WHO; 2015. Available from: http://www.who.int/ mediacentre/factsheets/fs404/en/. Accessed August 30, 2017.

2. Abbing HR. Health, healthcare and ageing populations in Europe, a human rights challenge for European health systems. Eur J Health Law. 2016;23(5):435-452.
3. Department of Health. Long Term Conditions Compendium of Information. 3rd ed. Leeds: DoH; 2012. Available from: https://www.gov. uk/government/uploads/system/uploads/attachment_data/file/216528/ dh_134486.pdf. Accessed August 30, 2017.

4. Yach D, Hawkes C, Gould CL, Hofman KJ. The global burden of chronic diseases: overcoming impediments to prevention and control. JAMA. 2004;291(21):2616-2622.

5. Maher RL, Hanlon J, Hajjar ER. Clinical consequences of polypharmacy in elderly. Expert Opin Drug Safety. 2014;13(1):57-65.

6. Centre for Pharmacy Postgraduate Education (CPPE). Polypharmacy. Manchester, UK: CPPE; 2016. Available from: https://www.cppe. ac.uk/learningdocuments/pdfs/cppe_polypharmacy_dl.pdf. Accessed September 10, 2017.

7. Duerden M, Avery T, Payne R. Polypharmacy and Medicines Optimisation: Making It Safe and Sound. London, UK: Kings fund; 2013. Available from: https://www.kingsfund.org.uk/sites/files/kf/field/ field_publication_file/polypharmacy-and-medicines-optimisationkingsfund-nov13.pdf. Accessed August 30, 2017.

8. Barnett MJ, Frank J, Wehring H, et al. Analysis of pharmacist-provided medication therapy management (MTM) services in community pharmacies over 7 years. J Manag Care Pharm. 2009;15(1):18-31.

9. Pharmaceutical Services Negotiating Committee (PSNC). NHS Employers Guidance on the Medicines Use Review service. London, UK: PSNC; 2013. Available from: http://www.nhsemployers.org/ /media/Employers/Documents/Primary\%20care\%20contracts/Pharmacy/MUR\%20 Guidance.pdf. Accessed February 22, 2018.

10. Dalton $\mathrm{K}$, Byrne $\mathrm{S}$. Role of the pharmacist in reducing healthcare costs: current insights. Integr Pharm Res Pract. 2017;6:37-46.

11. Latif A, Tariq S, Abbasi N, Mandane B. Giving voice to the medically under-served: a qualitative co-production approach to explore patient medicine experiences and improve services to marginalized communities. Pharmacy. 2018;6(1):E13.

12. NHS England. Service Level Agreement for a Local Service for the Provision of Domiciliary Medicine Use Reviews. Manfields: NHS England; 2016. Available from: http://psnc.org.uk/nottinghamshire-lpc/ wp-content/uploads/sites/21/2014/07/SLA-Domiciliary-MUR-2016-17. pdf. Accessed August 30, 2017.

13. Kojima T, Akishita M, Kameyama Y, et al. High risk of adverse drug reactions in elderly patients taking six or more drugs: analysis of inpatient database. Geriatr Gerontol Int. 2012;12(4):761-762.

14. Alhawassi TM, Krass I, Bajorek BV, Pont LG. A systematic review of the prevalence and risk factors for adverse drug reactions in the elderly in the acute care setting. Clin Interv Aging. 2014;9:2079-2086.

15. Latif A, Pollock K, Boardman HF. The contribution of the Medicines Use Review (MUR) consultation to counselling practice in community pharmacies. Patient Educ Couns. 2011;83(3):336-344.

16. Bradley F, Wagner AC, Elvey R, Noyce PR, Ashcroft DM. Determinants of the uptake of medicines use reviews (MURs) by community pharmacies in England: a multi-method study. Health Policy. 2008;88(2-3):258-2268.

17. Melton BL, Lai Z. Review of community pharmacy services: what is being performed, and where are the opportunities for improvement? Integr Pharm Res Pract. 2017;6:79-89.

18. Davies JE, Barber N, Taylor D. What do community pharmacists do? Results from a work sampling study in London. Int $J$ Pharm Pract. 2014;22(5):309-318.

19. Bradley F, Schafheutle EI, Willis SC, Noyce PR. Changes to supervision in community pharmacy: pharmacist and pharmacy support staff views. Health Soc Care Community. 2013;21(6):644-654.

20. Murray R. Community Pharmacy Clinical Services Review. London, UK: The King's Fund; 2016. Available from: https://www.england.nhs. uk/commissioning/wp-content/uploads/sites/12/2016/12/communitypharm-clncl-serv-rev.pdf. Accessed August 30, 2017.

21. Latif A, Pollock K, Anderson C, et al. Supporting underserved patients with their medicines: a study protocol for a patient/professional coproduced education intervention for community pharmacy staff to improve the provision and delivery of Medicine Use Reviews (MURs). BMJOpen. 2016;6(12):e013500. 
22. Davidson S, Rossall P. Age UK Evidence Review: Loneliness in Later Life. London: Age UK; 2014. Available from: https://www.ageuk.org. uk/globalassets/age-uk/documents/reports-and-publications/reportsand-briefings/health--wellbeing/age-uk-evidence-review-on-lonelinessjuly-2014.pdf. Accessed: August 30, 2017.

23. Qiu WQ, Dean M, Liu T, et al. Physical and mental health of homebound older adults: an overlooked population. J Am Geriatr Soc. 2010;58:2423-2428.

24. Vira T, Colquhoun M, Etchells E. Reconcilable differences: correcting medication errors at hospital admission and discharge. Qual Saf Health Care. 2006;15(2):122-126.
25. World Health Organization (WHO). Standard Operating Protocol: assuring medication accuracy at transitions in care action on patient safety (High 5s). Geneva: WHO; 2014. Available from: http://www. who.int/patientsafety/implementation/solutions/high $5 \mathrm{~s} / \mathrm{h} 5 \mathrm{~s}$-fact-sheet. pdf. Accessed August 30, 2017.

26. Ramsbottom HF, Fitzpatrick R, Rutter P. Post discharge medicines use review service for older patients: recruitment issues in a feasibility study. Int J Clin Pharm. 2016;38:208-212.

27. Greenhalgh T, Robert G, Macfarlane F, Bate P, Kyriakidou O. Diffusion of innovations in service organizations: systematic review and recommendations. Milbank Q. 2004;82(4):581-629.

\section{Publish your work in this journal}

Integrated Pharmacy Research and Practice is an international, peer-reviewed, open access, online journal, publishing original research, reports, reviews and commentaries on all areas of academic and professional pharmacy practice. This journal aims to represent the academic output of pharmacists and pharmacy practice with particular focus on integrated care. All papers are carefully
Submit your manuscript here: http://www.dovepress.com/integrated-pharmacy-research-and-practice-journal peer reviewed to ensure the highest standards as well as ensuring that we are informing and stimulating pharmaceutical professionals. The manuscript management system is completely online and includes a very quick and fair peer-review system, which is all easy to use. Visit http://www.dovepress.com/ testimonials.php to read real quotes from published authors. 